\title{
Two-month-old infants' sensitivity to allophonic differences
}

\author{
ELIZABETH A. HOHNE and PETER W. JUSCZYK \\ State University of New York, Buffalo, New York
}

\begin{abstract}
The present study investigated 2-month-olds' abilities to discriminate allophonic differences that are potentially useful in segmenting fluent speech. Experiment 1 investigated infants' sensitivity to the kind of distinction that may signal the presence or absence of a word boundary. When tested with the high-amplitude sucking procedure, infants discriminated pairs of items, such as "nitrate" versus "night rate" and "nikrate" versus "nike rate." By greatly reducing the potential contribution of prosodic differences to these contrasts, Experiment 2 evaluated whether the allophonic differences for $/ t /$ and $/ r /$ were sufficient for infants to distinguish the "nitrate" versus "night rate" pair. Infants distinguished "nitrate" from a cross-spliced version of "night rate," which differed only in the allophones for $/ \mathrm{t} /$ and $/ \mathbf{r} /$ that it included. Thus, infants appear to possess one of the prerequisite capacities (i.e., the ability to discriminate allophonic distinctions) necessary to use allophonic information in segmenting fluent speech.
\end{abstract}

Research over the past 25 years has revealed that infants possess many remarkable capacities for perceiving speech (for reviews, see Aslin, Pisoni, \& P. W. Jusczyk, 1983; Best, in press; P. W. Jusczyk, in press; Kuhl, 1987; Werker \& Tees, 1992). Not only are infants able to discriminate a wide range of speech contrasts from an early age (Bertoncini, Bijeljac-Babic, Blumstein, \& Mehler, 1987; Best, McRoberts, \& Sithole, 1988; Eimas, 1974; Eimas \& Corbit, 1973; Eimas, Siqueland, P. W. Jusczyk, \& Vigorito, 1971; Levitt, P. W. Jusczyk, Murray, \& Carden, 1988; Streeter, 1976; Trehub, 1976; Werker \& Tees, 1984), but they also display some capacity for coping with the sources of variability in the signal having to do with speaking rate and differences in talkers' voices (Eimas \& Miller, 1980a; P. W. Jusczyk, Pisoni, \& Mullennix, 1992; Kuhl, 1979, 1983; Miller \& Eimas, 1983). Although the possession of such capacities undoubtedly helps them in making sense of the stream of speech that they hear, infants still have much to learn about the specific relations that hold among the sounds in their native language. Not only do languages differ in the inventory of sounds that are used to form words (i.e., what phonetic segments they include), but they also differ in the way that phonetic segments can be combined within a word

Portions of the work reported here were presented at the Workshop on Cross-Language Speech Perception (Tampa, Florida, May 1992), the International Conference on Infant Studies (Miami Beach, May 1992), and the 98th Meeting of the Acoustical Society of America (Ottawa, April 1993). This investigation was supported by N.I.C.H.D. Research Grant HD-15795 to P.W.J. We wish to thank Ann Marie Jusczyk and Nancy Redanz for their help in running subjects. We are also grateful to LouAnn Gerken, Ann Marie Jusczyk, Paul Luce, Jim Sawusch, Erwin Segal, and J. David Smith for helpful comments that they made on earlier versions of this manuscript. Correspondence should be addressed to P. W. Jusczyk, Department of Psychology, Park Hall, SUNY at Buffalo, Buffalo, NY 14260-4110. (i.e., the phonotactic sequences they permit). Thus, one of the tasks involved in language acquisition is not only learning about what sounds occur in native language words, but also learning about any constraints that exist on where these sounds may appear in words in the language. For instance, the child acquiring English has to learn that the sound $/ \mathrm{y} /$ may occur in the middle or at the ends of words, but not at the beginning.

Information about the way that different phonetic segments are typically distributed in the language is obviously important in learning how sounds may be combined to form words. However, there is some reason to believe that such information could also serve a useful purpose in segmenting fluent speech into words. For example, it has been suggested that knowledge of the word contexts in which particular allophones appear could help adult listeners to determine word boundaries in fluent speech (Bolinger \& Gerstman, 1957; Christie, 1977; Church, 1987; Dutton, 1992; Lehiste, 1960; Nakatani \& Dukes, 1977; Umeda \& Coker, 1974). For example, the acoustic characteristics of $/ t /$ in English words are known to differ depending on the location of this segment within the word. Whereas $/ t /$ is aspirated in the initial position of syllables, it tends to be unaspirated when it occurs in final position (Umeda \& Coker, 1974). Conceivably, a listener who detects the difference between an aspirated and an unaspirated $/ t /$, and associates each with its typical position within words, could use information about the occurrence of these segments as cues to word boundaries in fluent speech. Indeed, Dutton (1992) has recently reported that duration of aspiration was the single most important cue that her adult listeners used in differentiating initial from final $/ \mathrm{t} / \mathrm{s}$ in English words (see also Lehiste, 1960).

The issue of when and how infants begin to segment fluent speech into words has not been widely studied. In 
fact, only recently have investigators begun to focus on the nature of the perceptual units that infants may form in processing fluent speech. Hirsh-Pasek et al. (1987; see also Kemler Nelson, Hirsh-Pasek, P. W. Jusczyk, \& Wright Cassidy, 1989) demonstrated that infants, as young as 7 months old, are sensitive to the presence of prosodic markers of clauses in fluent speech. A subsequent investigation indicated that American infants show sensitivity to prosodic marking of major phrasal units some time around 9 months of age (P. W. Jusczyk, Hirsh-Pasek, et al., 1992). Two more recent investigations have provided data that bear more directly on the ability of infants to segment fluent speech into words. Morgan (in press) has reported that 8-month-olds appear to be responsive to the types of regular rhythmic and distributional properties of strings of syllables that could be useful in segmenting words from fluent speech. Moreover, P. W. Jusczyk and Aslin (in press) found that $71 / 2^{-}$ month-olds familiarized with isolated versions of words demonstrated some recognition of these same words when they occurred in the sentential contexts.

These recent findings with infants suggest that the capacity to segment words from fluent speech is developing during the latter half of the first year. Potentially, there are a number of sources of information that infants could draw on in segmenting words from fluent speech. One possibility is that infants first learn to recognize words by hearing them spoken in isolation and then by matching some stored representation of their sound structure to information in fluent speech (Suomi, 1993). Another possibility is that infants draw upon potential prosodic cues to word boundaries in the input. For example, Cutler and her colleagues (Cutler, 1990; Cutler \& Butterfield, 1992; Cutler \& Carter, 1987; Cutler \& Norris, 1988) have pointed out that a high proportion of words used in English conversational speech begin with strong syllables and that listeners could use such information as a cue to potential word boundaries. Moreover, American 9-month-olds appear to be sensitive to this property of English words in that they listen significantly longer to words that follow a strong/weak, as opposed to a weak/strong, stress pattern (P. W. Jusczyk, Cutler, \& Redanz, 1993). However, there is still another possible source of information that infants could use to locate word boundaries in fluent speech. Namely, they might also be able to use the kind of information about allophonic variation that has been mentioned as a potential cue for adults' segmentation of words from fluent speech (e.g., Bolinger \& Gerstman, 1957; Church, 1987; Lehiste, 1960; Umeda \& Coker, 1974). Of course, there is no reason to assume that infants rely on only one such source of information to segment words from fluent speech. Instead, developing proficiency in segmenting fluent speech may require attention to a variety of different cues to potential word boundaries.

In the present investigation, we focus on only one potential source of information for segmenting fluent speech-namely, allophonic variation. Our aim is not to claim that this is the primary one that infants rely on. Rather, it is simply to determine whether infants even have some of the necessary prerequisite abilities to be able to use allophonic variation as a source of information about word boundaries in English. Consider what is necessary for allophonic variation to be usable as a cue to word boundaries. First, the distribution of these allophones in fluent speech has to correlate with boundaries. Second, infants must be able to discriminate the acoustic patterns corresponding to one allophone from those corresponding to another allophone. Third, infants need to be sensitive to the way in which allophones are typically distributed within words in the native language. ${ }^{1}$ Finally, they must have some capacity to use this distributional information during fluent speech perception. With respect to the first condition, the literature reviewed earlier suggests that there is some correlation between allophonic variants and English word boundaries (e.g., Bolinger \& Gerstman, 1957; Church, 1987; Hockett, 1958; Lehiste, 1960; Umeda \& Coker, 1974). What remains unclear is the extent to which the remaining conditions are satisfied. The aim of the present study was to take the first step in this regard by determining whether 2-month-old American infants are able to discriminate the kinds of allophonic contrasts that could provide information about English word boundaries.

\section{EXPERIMENT 1}

Although the speech perception literature provides many demonstrations of young infants' abilities to discriminate subtle speech contrasts, these studies have tended to focus on distinctions that are phonemic in the native language (e.g., Eimas, 1975; Eimas \& Miller, 1980b; Eimas et al., 1971; Morse, 1972). Our aim was to explore a contrast between phonetic segments which do occur regularly in native language speech, although not usually in the same phonetic contexts, and yet both segments are allophones of the same phoneme in the language. The critical feature was to find the kind of minimal contrast that could serve to indicate the presence or absence of a boundary between two words in the language. For this purpose, we chose a pair of items - "nitrate" versus "night rate"- that have often been used to illustrate how allophonic variation can cue word boundaries (e.g., Hockett, 1958; Lehiste, 1960; Nakatani \& Dukes, 1977). The broad phonemic transcriptions of the items in this pair are identical except for the presence of a word boundary marker separating the $/ t /$ and $/ r /$ in "night rate." However, the narrow phonetic transcriptions of these words indicate their allophonic differences. In particular, the first occurrence of " $t$ " in " $\mathrm{ni}$ trate" is aspirated, released, and retroflexed, and the following " $r$ " is devoiced, suggesting that it is part of a cluster. In contrast, the first " $t$ " in "night rate" is unaspirated, unreleased, and not retroflexed, and the following " $r$ " is voiced, suggesting that it is syllable initial. Together the absence of aspiration for the first " $t$ " in "night 
rate" and the voicing of the following " $r$ " suggests that the phoneme $/ t /$ is not syllable initial. To further test the generality of infants' abilities to distinguish the kind of allophonic variation that could signal the presence of word boundaries, we also decided to test an additional group on the nonword pair, "nikrate" versus "nike rate." Another reason for using this pairing is that it also allowed us to create additional pairs to investigate infants' abilities to discriminate medial contrasts that would be phonemic in English (i.e., "nikrate" vs. "nitrate" and "night rate" vs. "nike rate"). Inclusion of these phonemic contrasts would be helpful in sorting out whether a possible failure of infants to discriminate a pair such as "nitrate" versus "night rate" was due to a difficulty that infants might have with allophonic contrasts or to a general difficulty in discriminating contrasts in medial positions of words. Although there is evidence from some investigations that infants this age can discriminate medial contrasts that are phonemic in the target language (e.g., P. W. Jusczyk, Copan, \& Thompson, 1978; P. W. Jusczyk \& Thompson, 1978), there are also circumstances reported under which infants have difficulty with such contrasts (e.g., Karzon, 1985). Thus, a failure on the part of the infants to discriminate any of the medial contrasts would point to a general difficulty in discriminating distinctions in this position, whereas a failure only with the allophonic contrasts would be more apt to signal a difficulty with these types of distinctions.

\section{Method}

Subjects. Sixty infants ( 25 females and 35 males) from the Buffalo, New York area, with a mean age of 8 weeks 6 days (range, 6 weeks 2 days -12 weeks 5 days), were used in the final analysis. To obtain the 60 infants for this experiment, it was necessary to test 159 . The subjects were excluded for the following reasons: crying ( $41 \%)$, falling asleep prior to shift ( $18 \%)$, ceasing to suck during the course of the experiment (e.g., 2 consecutive minutes of zero level responding; $13 \%$ ), failure to achieve the habituation criterion within $24 \mathrm{~min}(10 \%)$, experimental error (9\%), repeatedly rejecting the pacifier ( $2 \%$ ), and miscellaneous (e.g., equipment failure, bowel movements, fire alarm; 7\%).

Stimuli. The stimuli consisted of natural tokens of the words "nitrate" and "night rate" and the nonwords "nikrate" and "nike rate." A male talker rehearsed the nonwords until he could produce them as easily and naturally as the word stimuli. The stimuli were recorded in the carrier sentence, "Teddy said to me". Recordings were made using an Electro-Voice Model D054 microphone, low-pass filtered (at $4.5 \mathrm{kHz}$ ) and digitized (via 12-bit digital-to-analog converter to a $10 \mathrm{kHz}$ sampling rate) and stored on a VAX 3100 . The stimuli were spliced out of the carrier sentence. Three different tokens for each stimulus were selected for use in the experiment. To obtain tokens of each stimulus type that were matched with those of other types as closely as possible in their overall duration and pitch, the talker recorded about 30 versions of each. The final versions of the tokens selected were equated in their overall durations $(609 \mathrm{msec})$ by removing individual pitch pulses from the vowels using a speech editor on the VAXStation. As a check on the intelligibility and discriminability of the tokens, a group of adults was asked to label these items and then to perform a same/different speeded forced-choice task. The results indicated that the tokens were identified with high reliability and the contrasting pairs were discriminable by adult listeners.
There were 12 tokens in all; 3 for each stimulus type. The digitized versions of the stimuli were transferred to a PDP 11/73 computer. They were accessed directly during the course of the experiment and reproduced at a $10-\mathrm{kHz}$ sampling rate, low-pass filtered at $4.8 \mathrm{kHz}$ and presented to the infant.

Design. There were 12 subjects assigned to each of five test groups. All three tokens of a particular stimulus type were presented to subjects during the preshift and postshift phases of the experiment. For the "nitrate versus night rate" group, the stimuli consisted of utterances of words that have distinct allophonic forms corresponding to a difference in word juncture. For the "nikrate versus nike rate" group, the stimuli were utterances of nonwords with distinct allophonic forms corresponding to a difference in the presence of a potential "word" juncture. The same stimuli were paired differently to create the "nitrate versus nikrate" group and the "night rate versus nike rate" group. These two groups tested infants' discrimination of the phonemic difference between $/ t /$ and $/ k /$ in the medial position of the utterances. Finally for the control group, the stimuli for both the preshift and the postshift periods consisted of the tokens of only one of the four stimulus types (e.g., "nitrate"). Each of the four types of stimuli served as a control pair for 3 subjects.

Apparatus. A blind nipple was connected to a Grass PT5 volumetric pressure transducer, which in turn was coupled to a Grass (Model 7) polygraph. A Schmitt trigger provided a digital output of the criterial high-amplitude sucking response. This output was relayed to a PDP 11/73 computer that recorded and saved the number of criterion responses on a minute-by-minute basis. In addition, the computer accessed the digitized words and nonwords and controlled the presentation of the auditory stimuli in response to a criterion-level sucking. The sounds were played out over a Kenwood (KA-3500) amplifier to a Pinnacle (PN5+) loudspeaker at a level of $72 \pm 2 \mathrm{~dB}(\mathrm{C}) \mathrm{SPL}$, which was $12 \mathrm{~dB}$ (C) above the ambient noise level in the testing room. The computer was programmed to record the level of baseline responding, detect the attainment of the criterion for habituation, select the appropriate set of postshift stimuli, and terminate the experiment after 4 min during the postshift period.

Procedure. Each 2-month-old was tested individually in a small laboratory room. The infant was placed in a reclining chair facing a blank wall approximately $1 \mathrm{~m}$ away. An image of flowers was projected on the wall for the entire test session. The picture was situated just above a loudspeaker through which the test stimuli were played. Each infant sucked on a blind nipple held in place by an experimenter who wore headphones and listened to recorded music throughout the test session. The music was played at a loudness level that effectively masked the sounds for the experimenter and caregiver (see Kemler Nelson et al., in press). A second experimenter in an adjacent room monitored the test apparatus.

The experimental procedure was a modification of the highamplitude sucking technique (Eimas et al., 1971; P. W. Jusczyk, 1985; Siqueland \& DeLucia, 1969). For each infant, the high-amplitude sucking criterion and the baseline rate of high-amplitude sucking were established prior to the presentation of any test stimuli. The criterion for high-amplitude sucking was adjusted to produce rates of 16-36 sucks/minute. After a baseline rate was established, the presentation of stimuli was made contingent on the rate of high-amplitude sucking. Criterion sucks resulted in the presentation of one stimulus. For infants in the test and control groups, the same type of stimulus (e.g., "nitrate") was presented throughout the preshift phase of the experiment. Presentation of the stimuli was counterbalanced across subjects. The maximum stimulus presentation rate was one stimulus per second. If the infant produced a burst of sucking with interresponse times less than $1 \mathrm{sec}$, then each response did not produce one presentation of a stimulus. Instead, the timing apparatus was reset so as to provide continuous auditory feedback for $1 \mathrm{sec}$ after the last response of the sucking burst. In any case, if the $1-\mathrm{sec}$ period would have 
ended in the middle of a stimulus, its ending was delayed until the stimulus was completed.

The criterion for habituation during the preshift phase of the experiment was a decrement in sucking rate of $25 \%$ or more over 2 consecutive minutes, compared with the rate in the immediately preceding minute. Timing of the postshift phase began with the presentation of the first stimulus after the habituation criterion had been achieved. At this point, the auditory stimulation was changed to that which was appropriate for the postshift phase of a given condition. Infants in the test groups were presented with the other member of the stimulus pair (e.g., "night rate" after hearing "nitrate" during the preshift phase), whereas infants in the control group were presented with the same type of stimulus (e.g., "nitrate"). The infants' sensitivity to changes in auditory stimulation was determined by calculating difference scores for preshift and postshift sucking rates and comparing the experimental and control groups on this measure. The postshift period lasted for $4 \mathrm{~min}$.

\section{Results}

For purposes of statistical comparison, the subjects' sucking rates were examined for four intervals: baseline minute, third minute before shift, average of Minutes 1 and 2 before shift, and average of the first $2 \mathrm{~min}$ after shift. These data were then used to calculate difference scores for each of the following rate comparisons: (1) acquisition of the sucking response (third minute before shift - baseline), (2) habituation (third minute before shift - average of the last $2 \mathrm{~min}$ before shift), and (3) release from habituation (average of the first $2 \mathrm{~min}$ after shift - average of the last 2 min before shift).

As is typically the case in studies employing the HAS procedure, subjects in all groups acquired the conditioned high-amplitude sucking response and attained the habituation criterion. To assess possible group differences during the preshift period, the sucking rates of each infant for the baseline minute and each of the last 3 min before shift were entered into an analysis of variance (ANOVA). The ANOVA revealed only the expected significant effect of minutes $[F(3,165)=145.94, p=$ $.0001]$. There was no evidence of any significant main effect for groups $[F(4,165)<1.0]$ or interaction of this variable with minutes $[F(12,165)<1.0]$.

The data for release from habituation during the postshift period are displayed in Figure 1. Planned comparisons using randomization tests for independent samples (Byrne, 1993; Siegel, 1956; Siegel \& Castellan, 1988) were used to assess postshift sucking performance. The release from habituation scores of each experimental group were compared with that of the control group, with the prediction that discrimination of the contrast would be indicated by significantly higher recovery scores for the experimental groups than for the controls. Most importantly, the results indicated that both comparisons involving allophonic distinctions relating to the potential word boundaries were discriminated by the infants ("nitrate vs. night rate," $p=.000735$; "nikrate vs. nike rate," $p=.000988$ ). ${ }^{2}$ The infants also gave evidence of discriminating the medial $/ \mathrm{t} / \mathrm{versus} / \mathrm{k} /$ contrast for both the "night rate versus nike rate" pair $(p=$ $.001813)$ and the "nitrate versus nikrate" pair $(p=$ $.032141)$. Thus, the infants were able to discriminate

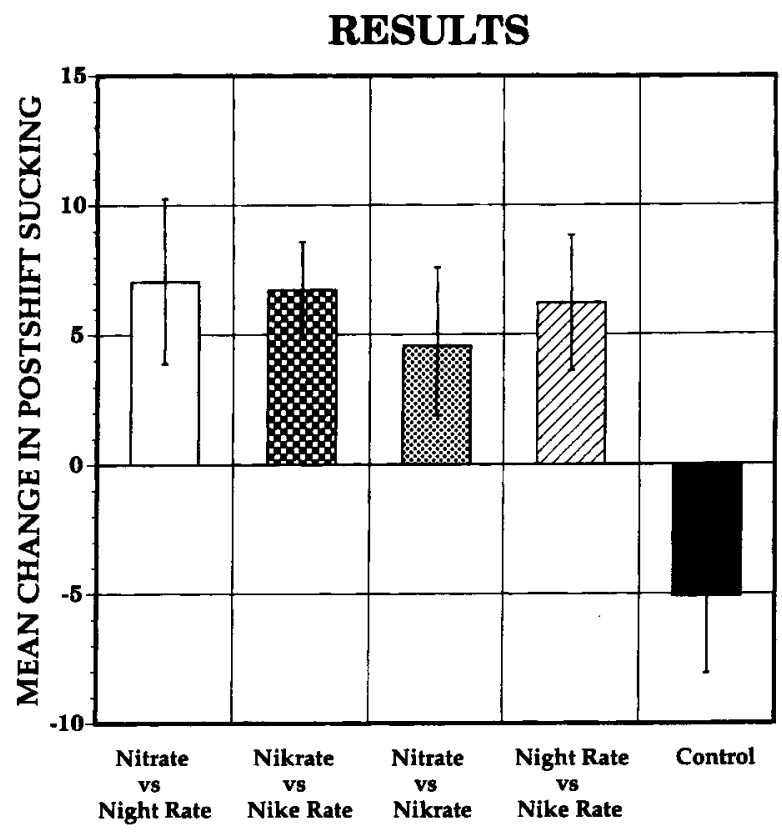

Figure 1. Mean change in postshift sucking for subjects in each test group of Experiment 1 . Scores were determined by taking the average sucking rates for the first 2 min of the postshift period and subtracting the average sucking rate for the last 2 min of the preshift period. Infants in the experimental groups heard a novel stimulus during the postshift period, whereas infants in the control groups heard the same stimulus as in the preshift period.

both the allophonic and the phonemic contrasts in the medial positions of these utterances.

\section{Discussion}

The critical comparisons in Experiment 1 were those in which one member of a stimulus pair included a word boundary that was absent from the other member of the pair (i.e., "nitrate" vs. "night rate" and "nikrate" vs. "nike rate"). The fact that 2-month-olds discriminated each pair suggests that they possess one of the prerequisites necessary to be able to use acoustic markers of word boundary. They can apparently detect the type of acoustic distinction that could indicate the presence of a word boundary. Moreover, in line with previous results (P. W. Jusczyk \& Thompson, 1978), there was evidence that 2-month-olds were able to discriminate a phonemic contrast between the stop consonant segments $/ \mathbf{t} /$ and $/ \mathbf{k} /$ in the medial position of utterances.

The present findings accord with those recently reported by Christophe, Dupoux, Bertoncini, and Mehler (1994), who studied French newborns' ability to discriminate pairs of disyllabic utterances that either contained or did not contain a word boundary. For example, the newborns were tested on their discrimination of disyllables, such as "mati," taken from a two-word sequence (e.g., "panorama typique") from other versions of the same disyllables taken from a single word (e.g., "mathematician"). However, in contrast to the present study, Christophe et al. were primarily interested in 
whether infants would discriminate these contrasts on the basis of prosodic differences (i.e., stress and accent) between the items. As in the present study, the newborns were found to discriminate stimuli containing a word boundary from those without a word boundary. However, because Christophe et al. found statistically reliable prosodic, but not allophonic, differences between members of their stimulus pairs, it appears that their infants were responding on the basis of prosodic differences connected with the presence of word boundaries.

Although the stimuli in Experiment 1 were chosen because they differed in terms of their allophones for $/ t /$ and $/ \mathrm{r} /$, we cannot completely rule out the possibility that the infants drew on other kinds of acoustic differences between the stimuli, such as their prosody. Thus, even though the stimuli contrasted in their allophonic properties, they were not perfectly matched with respect to other acoustic characteristics. For example, although an effort was made to match the items with respect to their overall pitch contours, there were slight differences among the stimuli. Similarly, the vowel durations of all the tokens were not perfectly equated. It is conceivable that differences of these sorts could also have contributed to the discriminability of the sets of tokens used in the present experiment. Consequently, to better determine whether the allophonic differences, themselves, provided a sufficient basis for the infants in discriminating pairs such as "nitrate" and "night rate," we conducted the following experiment.

\section{EXPERIMENT 2}

One means of ensuring that the critical differences distinguishing the stimuli are those associated with allophonic variation is to use cross-splicing to equate the stimuli with respect to other acoustic characteristics such as pitch contour, vowel length, and so on. Nakatani and Dukes (1977) used this method to study the role of allophonic variation in word segmentation by adult listeners. They switched portions of the speech in the regions around a word juncture, singly and in combination, to see how much each portion and their combinations influenced juncture perception. Parent utterances that differed in word juncture (e.g., "play taught" and "plate ought") were divided at critical portions in the utterances. Then, hybrid utterances were constructed using combinations of the portions of each utterance, including two replicas of the original utterances. The resulting items were played to subjects who identified them as one of four possible alternatives (e.g., "play ought," "play taught," "plate ought," or "plate taught"). In this way, Nakatani and Dukes were able to assess how much influence allophonic variation had on juncture perception.

The stimuli used in Experiment 2 were prepared in an analogous fashion. Utterances of "nitrate" and "night rate" were each divided in a way that allowed us to isolate the portion of the words corresponding to the $/ t /$ and
$/ \mathrm{r} /$ segments. ${ }^{3}$ Cross-splicing techniques were then used to create versions of "nitrate" and "night rate" in which the noncritical portions of these utterances were matched in terms of their overall acoustic and prosodic differences. If allophonic differences are a sufficient basis for infants to discriminate pairs such as "nitrate" and "night rate," then they should be able to discriminate these newly created stimulus pairs.

\section{Method}

Subjects. Thirty-six infants ( 15 male and 21 female) from the Buffalo, New York area, with a mean age of 8 weeks 4 days (range, 6 weeks 5 days-12 weeks 4 days), were used in the final analysis. To obtain the 36 infants for this experiment, it was necessary to test 110 . Subjects were excluded for the following reasons: crying $(43 \%)$, falling asleep prior to shift $(22 \%)$, ceasing to suck during

\section{Cross Splicing}

\section{Step 1:}

Start with $n$ it $r$ a $t e$

Splice out $t r$ and save it

And keep the frame $n i$... a te

Start with $\mathbb{N} \mathbb{I} \mathbb{G}$ II $\mathbb{R} \mathbb{A} \mathbb{B}$

Splice out $\mathbb{I} \mathbb{R}$ and save it

And keep the frame $\mathbb{N} I \mathbb{G} \mathbb{I}$... $A \mathbb{I} \mathbb{B}$

\section{Step 2:}

\section{Take the $t r$ from nitrate}

Insert into $\mathbb{N} \mathbb{G} \mathbb{H} \ldots \mathbb{A} \mathbb{E}$

To create hybrid $\mathbb{N} I I G B]$ tr A IS IS which sounds like "nitrate"

Take the $\mathbb{I}$ from night rate

$$
\text { Insert into } n i \ldots a t e
$$

$$
\begin{aligned}
& \text { To create hybrid } n i \mathbb{T} \text { a te } \\
& \text { which sounds like "night rate" }
\end{aligned}
$$

Figure 2. Depiction of the steps in the cross-splicing procedure used to prepare the hybrid stimuli for Experiment 2. 
the course of the experiment (e.g., 2 consecutive minutes of zero level responding; $18 \%$ ), failure to achieve the habituation criterion within $24 \mathrm{~min}(8 \%)$, repeatedly rejecting the pacifier $(4 \%)$, and miscellaneous (e.g., experimental error, bowel movements, fire alarm; 5\%)

Stimuli. The stimuli were prepared from one of the "nitrate" and one of the "night rate" tokens from Experiment 1 . In addition to the original versions of these tokens, two new modified tokens were created by cross-splicing portions of the original tokens. Cross-splicing was accomplished in two steps using a speech waveform editor. In the first step, we spliced out the /tr/ segments in the words "nitrate" and "night rate," leaving the vowel and consonants on either side intact. Thus, we had two $/ \mathrm{tr} /$ sequences that corresponded to the different utterances and two "ni _ _ ate" frames that were missing their $/ \mathrm{tr} / \mathrm{s}$, as is illustrated in Figure 2 . In the second step, we spliced the /tr/ segments from the word "nitrate" into the " ni _ate" frame from the parent phrase "night rate." In so doing, we were able to change the original token of "night rate" into a new hybrid token that sounded like "nitrate." We refer to this stimulus as the "hybrid nitrate." Note that the consonants and vowels surrounding the $/ \mathrm{t} /$ and $/ \mathrm{r} /$ in the parent phrase "night rate" and the "hybrid nitrate" were identical. Furthermore, the durations of the stretches of speech corresponding to the " $t r$ " and " $t \#$ " were identical (149.5 msec). Consequently, the "hybrid nitrate" token and the original "night rate" token were distinguished only by the allophones associated with an unaspirated versus aspirated $/ \mathrm{t} /$ and the fully voiced $/ \mathrm{r} /$ versus the devoiced $/ r /$. An illustration of the waveform of this hybrid "nitrate" token is shown in Figure 3 along with waveforms of the original "nitrate" and "night rate" tokens used in the present experiment. One obvious difference between the original "night rate" token and the original and hybrid tokens of "nitrate" is the presence of prominent aspiration in the latter two tokens.

Comparable procedures were followed to create a "hybrid night rate" token, which was to be paired with the original "nitrate" token. The / $\mathrm{tr} /$ segment that had been spliced out of the utterance "night rate" was inserted into the "ni _ ate" frame derived from the original token of "nitrate." Thus, when contrasted with the original token of "nitrate," the "hybrid night rate" differed only in terms of its $/ t / /$ and $/ r /$ allophones. Tests with adult listeners indicated that the "hybrid nitrate" token was clearly perceived as "nitrate" and the "hybrid night rate" token as "night rate."

Design. Twelve subjects were assigned to each of three test groups. Although we did not expect to find differences in infants' responses to the "night rate versus hybrid nitrate" pair, as opposed to the "nitrate versus hybrid night rate" pair, we decided to test both sets of contrasts. Consequently, one experimental group was presented with a contrast between the original token of "night rate" and the "hybrid nitrate" token, and another experimental group was presented with the contrast between the original token of "nitrate" and the "hybrid night rate" token. In addition, there was a control group who heard the same stimulus for both the preshift and the postshift phases of the experiment. Each of the four types of stimuli served as a control pair for 3 subjects.

Apparatus and Procedure. These were identical to what was described for Experiment 1

\section{Results and Discussion}

The data were analyzed as in Experiment 1. Difference scores were calculated for each subject to assess (1) acquisition of the sucking response, (2) habituation to the preshift stimuli, and (3) release from habituation during the first 2 min of the postshift period. As in Experiment 1, all groups acquired the conditioned response and habituated to the preshift stimulus. Moreover, an ANOVA used to assess possible group differences during the baseline minute and each of the last 3 preshift minutes revealed only the anticipated significant effect of minutes $[F(3,99)=72.42, p=.0001]$. There was no evidence of any significant main effect for groups $[F(2,99)<1.0]$ or interaction of this variable with minutes $[F(6,99)<1.0]$.

The data for release from habituation during the postshift period are shown in Figure 4. As in Experiment 1, postshift sucking performance was analyzed by planned comparisons using randomization tests for independent samples, with the prediction that discrimination would be evidenced by significantly higher recovery scores for the experimental groups than for the control group. Both the "night rate versus hybrid nitrate" $(p=.024339)$ and the "nitrate versus hybrid night rate" $(p=.03657)$ groups differed significantly from the control group. In addition, a comparison of the recovery scores for the two experimental groups indicated that they did not differ significantly from each other $(p=.360881)$. Thus, even when the prosodic and acoustic characteristics of the stimuli were carefully controlled, the infants were able to use the remaining allophonic differences to distinguish the test items. These results suggest that infants are at least sensitive to the acoustic correlates of allophonic differences that could signal the presence of word boundaries in fluent speech.

However, another possible interpretation of the present results is that the infants based their discrimination of the hybrid versus original tokens on discontinuities introduced when the hybrid tokens were cross-spliced. Although the editing of hybrid tokens was done by cross-splicing only at zero crossings and at the end of one vocal pulse before the beginning of the next pulse, it is possible that subtle acoustic differences (e.g., minor changes in pitch contour or tracking of the formants) were introduced. Nevertheless, any such differences, if present, were not large enough for adults to detect and use. ${ }^{4}$ Moreover, given the obvious large differences in voiceless stop aspiration between the pairs of original and hybrid tokens, there is little reason to believe that infants would use any subtle acoustic differences incurred in editing as a basis for discrimination, rather than the much larger natural differences. Indeed, we experimented with the consequences of greatly reducing the amplitude of the aspiration of the / $t$ / in the "hybrid nitrate" token. When the amplitude of the aspiration was reduced by $20 \mathrm{~dB}$, adult listeners' perception of this token changed from "nitrate" to "night rate." Thus, the presence of aspiration cue critically affected whether adults heard this hybrid token as either "nitrate" or "night rate." Given this finding, it seems reasonable to assume that the infants' discrimination of the tokens was also based upon the presence of salient allophonic differences of this sort.

It is also worth noting that the differences between the experimental groups and the control group in Experiment 2 tended to be smaller than that observed between the "nitrate versus night rate" group and the control group of Experiment 1 . We verified this by analyzing the 
(a)

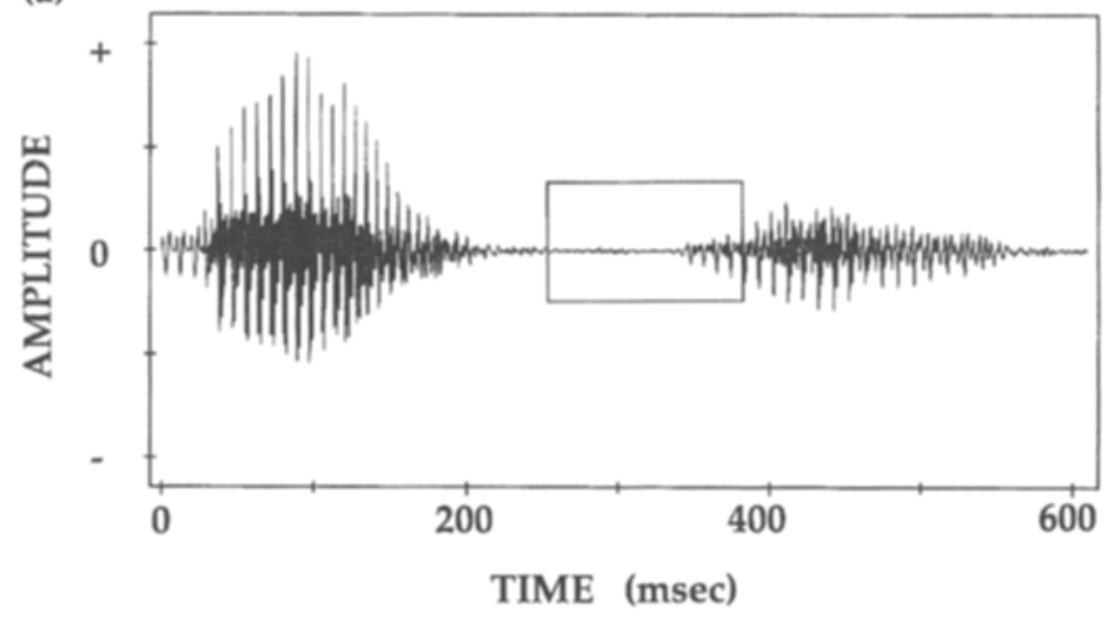

(b)

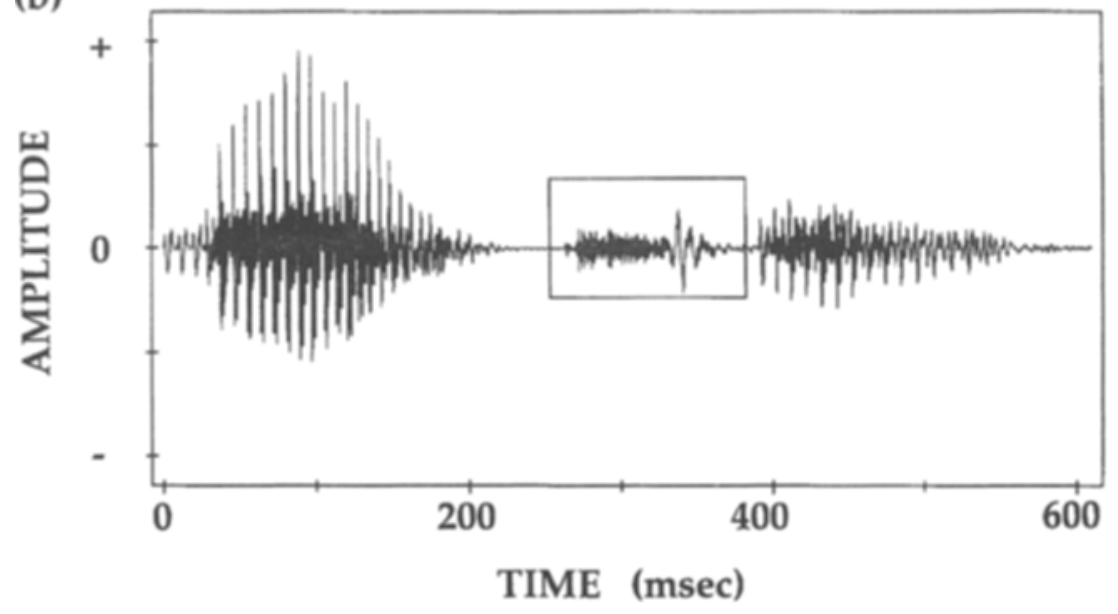

(c)

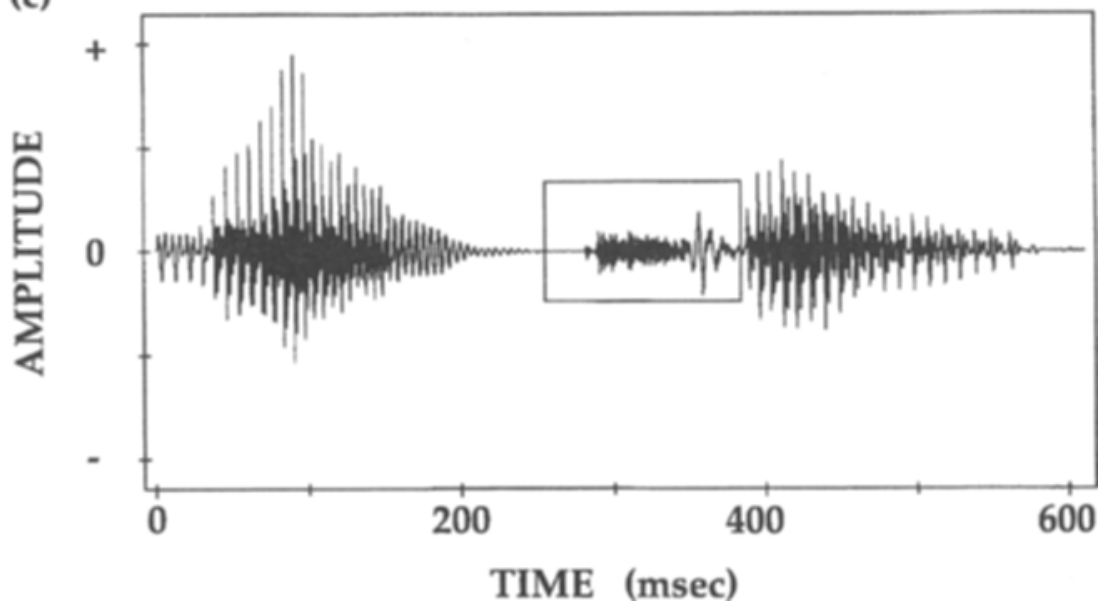

Figure 3. Waveforms of (a) the original token of "night rate," (b) the hybrid token of "nitrate," (c) the original token of "nitrate." Note that the boxed-in area of the waveforms corresponds to the information about the $/ t /$ and $/ \mathbf{r} /$ segments that were interchanged in producing the hybrid tokens. Thus, the waveform in (b) has the same frame as in (a) but the same $/ t /$ and $/ r /$ (i.e., the boxed-in stretch of speech) as in (c). 


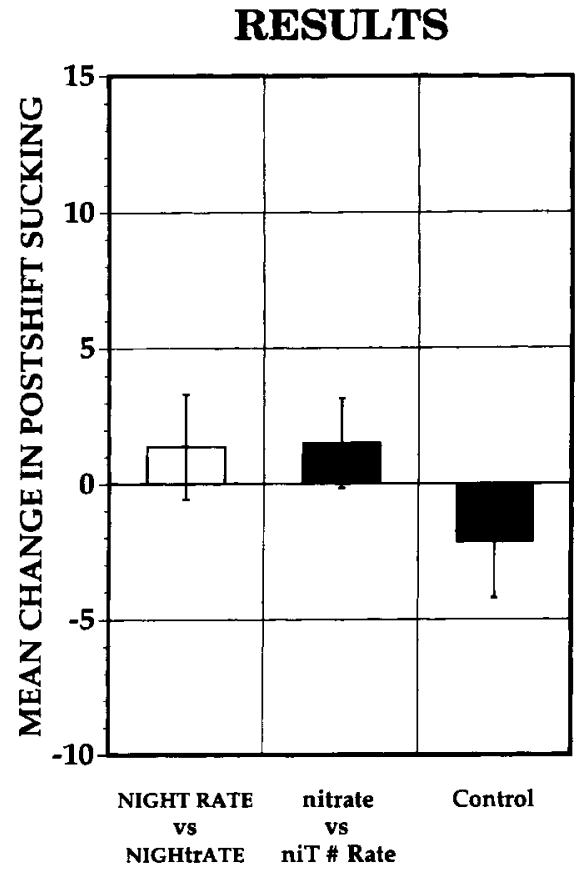

Figure 4. Mean change in postshift sucking for subjects in each test group of Experiment 2. Scores were determined by taking the average sucking rates for the first 2 min of the postshift period and subtracting the average sucking rate for the last $2 \mathrm{~min}$ of the preshift period. Infants in the experimental groups heard a novel stimulus during the postshift period, whereas infants in the control groups heard the same stimulus as in the preshift period.

data from the "nitrate versus night rate" group and control group from Experiment 1 along with the combined experimental groups and control group from Experiment 2 in an ANOVA of a 2 (experiment) $\times 2$ (treatment) design. This analysis indicated that the main effect for treatment was significant $[F(1,56)=20.23$, $p<.0001]$, but the main effect of experiment was not $[F(1,56)<1.0]$. Most importantly, there was a significant interaction between experiment and treatment $[F(1,56)=4.26, p<.05]$, confirming that the difference between the treatment groups was greater in Experiment 1 . This suggests that the infants in Experiment 1 may also have benefited from the presence of prosodic and other acoustic differences in discriminating the original tokens of "nitrate" and "night rate." Nevertheless, the results of the Experiment 2 indicate that even when these other prosodic and acoustic differences were not available, the remaining allophonic differences provided infants with a sufficient basis for discriminating the contrast between "nitrate" and "night rate."

\section{GENERAL DISCUSSION}

Although the main focus of the present investigation was on the discrimination of allophonic differences, our findings actually add new information about several dif- ferent aspects of infant speech capacities. For example, although the comparable contrast between the voiced stops /d/ and /g/ has been shown to be one that infants this age can discriminate (Eimas, 1974; P. W. Jusczyk, 1977; Morse, 1972), the phonemic contrast between the voiceless stops $/ \mathrm{t} /$ and $/ \mathrm{k} /$ is one that, to our knowledge, has not been explored in previous studies with infants. Thus, the present findings add $/ \mathrm{t} /$ versus $/ \mathrm{k} /$ to the inventory of speech contrasts that infants have been shown to discriminate. In addition, infants in the present study also discriminated a contrast between allophones of the same phoneme in English. There is some precedent for the latter finding. Werker and Lalonde (1988) found that 6-8-month-olds, but not older infants, from Englishspeaking homes were able to distinguish certain place of articulation contrasts that are phonemic in Hindi but that, when they occur in English, would be allophonic variants of $/ \mathrm{d} /$. One difference between the allophonic contrasts from the present study and those examined by Werker and Lalonde is that the latter ones appear to bear no systematic relation to junctural cues. It would be interesting to know whether there are any differences that emerge in development in the perception of allophonic differences that mark word boundaries versus other kinds of allophonic differences present in native language words.

In addition to providing new data on the types of speech contrasts that infants can discriminate, the present study provides further confirmation of infants' ability to discriminate contrasts in utterance medial positions. The fact that the infants were able to discriminate the $/ \mathrm{t} / \mathrm{versus} / \mathrm{k} / \mathrm{contrast}$ even when it occurred in an unstressed syllable (as was the case for "nikrate" vs. "nitrate") accords with earlier findings reported by Jusczyk and his colleagues (P. W. Jusczyk et al., 1978; P. W. Jusczyk \& Thompson, 1978; but see Karzon, 1985). Thus, medial contrasts do not necessarily have to be stressed in order for infants to detect them.

Note that throughout the paper we have referred to the distinctions being tested as "allophonic contrasts." This is certainly an apt description from the native Englishspeaker's point of view. However, it does not necessarily follow that infants perceive the distinction between "tr" and "t\#r" as an allophonic one. Rather, they might simply perceive the contrast as one between one acoustic pattern and another. In other words, we are not making any claims to the effect that infants even perceive the different variants as belonging to the same phonemic category. Nor is such an assumption necessary for them to be able to use the distinction between "tr" and " $\mathrm{tH} r$ " to cue the presence of possible word boundaries. What is required is that the infants at least have the capacity to distinguish the acoustic characteristics corresponding to one of these allophones from those corresponding to the other. At the same time, although our findings show that infants have the capacity to distinguish one acoustic pattern from another, what makes these particular patterns special is that they even- 
tually do convey a linguistically relevant distinction that fluent speakers could use in segmenting speech.

In raising the possibility that infants could use allophonic variation as a cue to word boundaries in English, we noted that a number of different conditions had to hold for this conjecture to be plausible. The first condition had to do with the availability of such information in fluent speech. As we indicated earlier, findings from earlier studies give some reason to believe that the necessary information is available in the speech stream (Bolinger \& Gerstman, 1957; Church, 1987; Hoard, 1966; Hockett, 1958; Lehiste, 1960; Umeda \& Coker, 1974). The remaining three conditions that we outlined all had to do with infants' abilities to make use of available allophonic information. The present results speak to the condition regarding the discriminability of the allophones. They indicate that infants have at least some ability to discriminate the kind of variation that could cue the presence of word boundaries in fluent speech. Just how extensive this ability is remains to be determined. In the meantime, how likely is it that the other two conditions are met by the language learner? The third condition has to do with the ability to track the distribution of the allophones in the input (i.e., to note the utterance position in which a particular allophone is likely to appear). Performing such a distributional analysis seems as though it would be beyond the reach of an infant. However, there is growing evidence that, during the second half of the first year, infants develop sensitivity to distributional properties of various aspects of native language sound patterns. Most critical, for the present purposes, are the results suggesting that sensitivity to characteristic phonetic sequences of native language words is developing between 6- and 9-months of age. For example, P. W. Jusczyk, Friederici, Wessels, Svenkerud, and A. M. Jusczyk (1993) found that 9-month-olds who heard lists of unfamiliar words that contained phonetic sequences, which were either permissible or impermissible in the native language, listened significantly longer to the words with the permissible sequences. This suggests that by this age infants have picked up information about how phonetic segments are typically combined in words in the native language (see also Friederici \& Wessels, 1993). Moreover, there is also recent evidence indicating that infants at this age are sensitive to the particular kinds of sequences that frequently occur in native language words. P. W. Jusczyk, Luce, and Charles-Luce (in press) found that when 9-month-olds were presented with lists of nonwords, all of which consisted of permissible phonetic sequences, the infants listened significantly longer to lists containing the phonetic sequences that occur most frequently in native language words. Although these findings do not establish that infants track how allophones are distributed in words, they do indicate that infants are at least becoming more sensitive to how phonetic information is distributed in words in the native language. The remaining condition that we raised with respect to the use of allophonic variation had to do with the ability to actually use information about the distribution of allophones during on-line speech processing. As mentioned earlier, some recent investigations provide reason to believe that infants around 8 months of age have some capacity to detect sound patterns corresponding to familiar words in fluent speech (P. W. Jusczyk \& Aslin, 1994; Morgan, in press). Whether allophonic cues are helpful in this context has not yet been demonstrated. One indication that allophonic cues do assist infants at this age to segment fluent speech would be to show that certain word boundaries in the input are more easily detected when such cues are available than when they are absent. We are presently working on methods of investigating this.

In closing, we would like to reiterate that our claim is that allophonic variation is a potential source of information for infants about word boundaries in fluent speech. We are not arguing that infants exclusively rely on allophonic cues for this purpose. As noted earlier, and as Christophe et al. (1994) have shown, prosodic cues and other kinds of information may also be called upon to help infants in segmenting words from fluent speech. Indeed, the performance of infants in discriminating sequences containing word boundaries from those without such boundaries was enhanced when other acoustic information, in addition to allophonic differences, was available (i.e., the size of the effects in Experiment 1 as compared with that in Experiment 2). Therefore, to the extent that allophonic cues are used, it is likely that they constitute only one of a number of different sources of information that infants draw on in learning to segment words from the speech stream.

\section{REFERENCES}

Aslin, R. N., Pisoni, D. B., \& Jusczyk, P. W. (1983). Auditory development and speech perception in infancy. In M. M. Haith \& J. J. Campos (Eds.), Infancy and the biology of development (pp. 573687). New York: Wiley.

Bertoncini, J., Bijeluac-Babic, R., Blumstein, S. E., \& Mehler, J. (1987). Discrimination in neonates of very short CV's. Journal of the Acoustical Society of America, 82, 31-37.

BEST, C. T. (in press). Learning to perceive the sound patterns of English. In C. Rovee-Collier \& L. P. Lipsitt (Eds.), Advances in infancy research. Norwood, NJ: Ablex.

Best, C. T., McRoberts, G. W., \& Sithole, N. M. (1988). Examination of the perceptual re-organization for speech contrasts: Zulu click discrimination by English-speaking adults and infants. Journal of Experimental Psychology: Human Perception \& Performance, 14, 345-360.

Bolinger, D. L., \& Gerstman, L. J. (1957). Disjuncture as a cue to constraints. Word, 13, 246-255.

BYRNE, M. D. (1993). A better tool for the cognitive scientist's toolbox: Randomization statistics. In W. Kintsch (Ed.), Proceedings of the 15th Conference of the Cognitive Science Society (pp. 289-293). Hillsdale, NJ: Erlbaum.

Christie, W. M. J. (1977). Some multiple cues for juncture in English. General Linguistics, 17, 212-222.

Christophe, A., Dupoux, E., Bertoncini, J., \& Mehler, J. (1994). Do infants perceive word boundaries? An empirical study of the bootstrapping of lexical acquisition. Journal of the Acoustical Society of America, 95, 1570-1580. 
Church, K. (1987). Phonological parsing and lexical retrieval. Cognition, 25, 53-69.

CutLer, A. (1990). Exploiting prosodic probabilities in speech segmentation. In G. T. M. Altmann (Ed.), Cognitive models of speech processing: Psycholinguistic and computational perspectives (pp. 105-121). Cambridge, MA: MIT Press.

CUtLer, A., \& ButTerfield, S. (1992). Rhythmic cues to speech segmentation: Evidence from juncture misperception. Journal of Memory \& Language, 31, 218-236.

Cutler, A., \& CARTER, D. M. (1987). The predominance of strong initial syllables in the English vocabulary. Computer Speech \& Language, 2, 133-142.

CUTLER, A., \& Norris, D. G. (1988). The role of strong syllables in segmentation for lexical access. Journal of Experimental Psychology: Human Perception \& Performance, 14, 113-121.

DUTTON, D. (1992). The role of allophonic variation in the perception of word boundaries. Unpublished doctoral dissertation, State University of New York at Buffalo.

Eimas, P. D. (1974). Auditory and linguistic processing of cues for place of articulation by infants. Perception \& Psychophysics, 16, 513-521.

Eimas, P. D. (1975). Auditory and phonetic coding of the cues for speech: Discrimination of the [r-1] distinction by young infants. Perception \& Psychophysics, 18, 341-347.

EimAs, P. D., \& CorBIT, J. D. (1973). Selective adaptation of linguistic feature detectors. Cognitive Psychology, 4, 99-109.

Eimas, P. D., \& Miller, J. L. (1980a). Contextual effects in infant speech perception. Science, 209, 1140-1141.

Eimas, P. D., \& Miller, J. L. (1980b). Discrimination of the information for manner of articulation. Infant Behavior \& Development, 3 , 367-375.

Eimas, P. D., Siqueland, E. R., Jusczyk, P. W., \& Vigorito, J. (1971). Speech perception in infants. Science, 171, 303-306.

FrIEDERICI, A. D., \& WesseLs, J. M. I. (1993). Phonotactic knowledge and its use in infant speech perception. Perception \& Psychophysics, 54, 287-295.

Hirsh-Pasek, K., Kemler Nelson, D. G., Jusczyk, P. W., Wright CAssidy, K., DRuss, B., \& KenNedy, L. (1987). Clauses are perceptual units for young infants. Cognition, 26, 269-286.

HoARD, J. E. (1966). Juncture and syllable structure in English. Phonetica, 15, 96-109.

HoCKETT, C. F. (1958). A course in modern linguistics. New York: Macmillan.

JusCZYK, P. W. (1977). Perception of syllable-final stops by twomonth-old infants. Perception \& Psychophysics, 21, 450-454.

JUSCZYK, P. W. (1985). The high amplitude sucking procedure as a methodological tool in speech perception research. In G. Gottlieb \& N. A. Krasnegor (Eds.), Measurement of audition and vision in the first year of life: A methodological overview (pp. 195-222). Norwood, NJ: Ablex.

JUSCZYK, P. W. (in press). Language acquisition: Speech sounds and the beginnings of phonology. In J. L. Miller \& P. D. Eimas (Eds.), Handbook of perception and cognition: Speech, language, and communication. Orlando, FL: Academic Press.

JUSCZYK, P. W., \& AsLiN, R. N. (in press). Infants' detection of word shapes in fluent speech. Cognitive Psychology.

JusczYK, P. W., CopaN, H., \& Thompson, E. (1978). Perception by two-month-olds of glide contrasts in multisyllabic utterances. Perception \& Psychophysics, 24, 515-520.

JUSCZYK, P. W., CUTLER, A., \& REDANZ, N. J. (1993). Infants' preference for the predominant stress patterns of English words. Child Development, 64, 675-687.

Jusczyk, P. W., Fruederici, A. D., Wessels, J. M., Svenkerud, V. Y., \& JUSCZYK, A. M. (1993). Infants' sensitivity to the sound patterns of native language words. Journal of Memory \& Language, 32, 402420.

Jusczyk, P. W., Hirsh-Pasek, K., Kemler Nelson, D. G., Kennedy, L., WoODWARD, A., \& PiWOZ, J. (1992). Perception of acoustic correlates of major phrasal units by young infants. Cognitive Psychology, 24, 252-293.
JusCzyK, P. W., LuCE, P. A., \& Charles-LuCE, J. (in press). Infants' sensitivity to phonotactic patterns in the native language. Journal of Memory \& Language.

Jusczyk, P. W., Pisoni, D. B., \& Mullennix, J. (1992). Some consequences of stimulus variability on speech processing by 2-monthold infants. Cognition, 43, 253-291.

JusczyK, P. W., \& Thompson, E. J. (1978). Perception of a phonetic contrast in multisyllabic utterances by two-month-old infants. Perception \& Psychophysics, 23, 105-109.

KARZON, R. G. (1985). Discrimination of a polysyllabic sequence by one- to four-month-old infants. Journal of Experimental Child Psychology, 39, 326-342.

Kemler Nelson, D. G., Hirsh-Pasek, K., Jusczyk, P. W., \& Wright CAssidy, K. (1989). How prosodic cues in motherese might assist language learning. Journal of Child Language, 16, 55-68.

Kemler Nelson, D. G., JusczyK, P. W., Mandel, D. R., Myers, J., Turk, A., \& Gerken, L. A. (in press). The Headturn Preference Procedure for testing auditory perception. Infant Behavior \& Development.

KuhL, P. K. (1979). Speech perception in early infancy: Perceptual constancy for spectrally dissimilar vowel categories. Journal of the Acoustical Society of America, 66, 1668-1679.

KuHL, P. K. (1983). Perception of auditory equivalence classes for speech in early infancy. Infant Behavior \& Development, 6, 263-285.

KuHL, P. K. (1987). Perception of speech and sound in early infancy. In P. Salapatek \& L. Cohen (Eds.), Handbook of infant perception (pp. 275-381). New York: Academic Press.

LEHISTE, I. (1960). An acoustic-phonetic study of internal open juncture. New York: S. Karger.

LevitT, A., JusczyK, P. W., Murray, J., \& Carden, G. (1988). The perception of place of articulation contrasts in voiced and voiceless fricatives by two-month-old infants. Journal of Experimental Psychology: Human Perception \& Performance, 14, 361-368.

Miller, J. L., \& EImAS, P. D. (1983). Studies on the categorization of speech by infants. Cognition, 13, 135-165.

MORGAN, J. L. (in press). Converging measures of speech segmentation in prelingual infants. Infant Behavior \& Development.

MoRse, P. A. (1972). The discrimination of speech and nonspeech stimuli in early infancy. Journal of Experimental Child Psychology, $13,477-492$

NAKATANI, L., \& DUKEs, K. (1977). Locus of segmental cues for word juncture. Journal of the Acoustical Society of America, 62, 714-719.

SIEGEL, S. (1956). Nonparametric statistics for the behavioral sciences. New York: McGraw-Hill.

Siegel, S., \& CASTEllaN, N. J. (1988). Nonparametric statistics for the behavioral sciences (2nd ed.). New York: McGraw-Hill.

Siqueland, E. R., \& DeLuCIa, C. A. (1969). Visual reinforcement of non-nutritive sucking in human infants. Science, 165, 1144-1146.

STREETER, L. A. (1976). Language perception of 2-month old infants shows effects of both innate mechanisms and experience. Nature, 259, 39-41.

Suomi, K. (1993). An outline of a developmental model of adult phonological organization and behavior. Journal of Phonetics, 21, 29-60.

TREHUB, S. E. (1976). The discrimination of foreign speech contrasts by infants and adults. Child Development, 47, 466-472.

UMEDA, N., \& CoKER, C. H. (1974). Allophonic variation in American English. Journal of Phonetics, 2, 1-5.

WERKER, J. F., \& LALONDE, C. E. (1988). Cross-language speech perception: Initial capabilities and developmental change. Developmental Psychology, 24, 672-683.

WerkeR, J. F., \& TEES, R. C. (1984). Cross-language speech perception: Evidence for perceptual reorganization during the first year of life. Infant Behavior \& Development, 7, 49-63.

WERKER, J. F., \& TEES, R. C. (1992). The organization and reorganization of human speech perception. Annual Review of Neuroscience, 15, 377-402.

WoOdWARD, J. Z., \& ASLIN, R. N. (1990, April). Segmentation cues in maternal speech to infants. Paper presented at the 7 th Biennial Meeting of the International Conference on Infant Studies, Montreal 


\section{NOTES}

1. Note that this last point would seem to require that they have at least some exposure to isolated words to work out such distributions. There are indications that at least some of the speech directed toward language-learning infants does consist of isolated words (Woodward \& Aslin, 1990).

2 . Note that randomization tests yield an exact probability based on an evaluation of the likelihood of obtaining a particular pattern of scores based on all possible permutations of these scores. For example, in each comparison between an experimental group and a control group (with sample sizes of 12 subjects each), there are $2,704,156$ possible outcomes. In the case of the comparison against the control group for the "nitrate versus night rate" group, the outcome obtained was the 1,987 th most extreme outcome, which yielded the exact probability indicated in the text. With large sample sizes, it is sometimes necessary to use an estimate based on the $t$ statistic. However, in the present study, we were able to calculate the exact probability using an implementation of the program in Siegel and Castellan (1988).

3. Note that the allophonic variation between the stretches of speech corresponding to " $\mathrm{tr}$ " and " $\mathrm{t} \mathrm{H}$ " is likely to include micro- prosodic (timing) differences along with other prominent differences having to do with the duration and amplitude of aspiration of the $/ t /$ and voicing characteristics of the $/ \mathrm{r} /$. However, our own measurements of the stimuli indicated that any such microprosodic differences are trivial, relative to the aspiration and voicing differences present in the critical segments.

4. Specifically, we tested adults' ability to detect whether the tokens were natural or hybrids. Ten adults listened to pairs of stimuli, which consisted of either 2 natural tokens, 2 hybrid tokens, or 1 natural and 1 hybrid token. On each trial, subjects were asked to write " $N$ " if both tokens sounded as though they were natural tokens and " $\mathrm{H}$ " if one or both tokens sounded like a "spliced hybrid" token. Performance in detecting the presence of the hybrid tokens in the pairs was at chance $[t(9)=-.70, p=.50]$. Thus, any acoustic changes introduced in editing the hybrid stimuli were not discriminable for adult listeners.

(Manuscript received January 26, 1994; revision accepted for publication May 27, 1994.) 